\title{
Editorial
}

Psychotherapy

and Psychosomatics

\section{Overcoming the Crisis of Clinical Research}

\author{
Giovanni A. Fava ${ }^{a, c}$ Fiammetta Cosci ${ }^{b}$ Elena Tomba ${ }^{a}$ \\ ${ }^{a}$ Department of Psychology, University of Bologna, Bologna, and ${ }^{b}$ Department of Health Sciences, University of

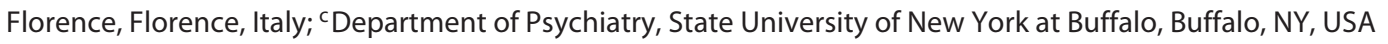

Part of the challenge and, at the same time, fascination of being a clinician lies in applying scientific methods in the care of patients and in understanding disease [1]. Greater knowledge should result in significant benefits for the patients, and in a sense of continued development on the part of the physician. We are witnessing, however, a progressive detachment of clinicians from research that is often accompanied by a sense of personal stagnation and tiredness [2]. Such detachment is primarily the consequence of the current crisis of clinical research: influential randomized trials are generally done by and for the benefits of the industry, guidelines serve vested interests, and national and federal research funds are funneled almost exclusively to research with little relevance to health outcomes [3]. In the late 1970s, Engel [4] pointed to the dangers of the alliance between commercial interests in medicine and biomedical reductionism. Indeed, corporate interest in medical science is likely to highlight the importance of single etiological factors and therapeutic agents in the management of disease $[5,6]$.

Twenty years ago this journal anticipated the current medical scenario dominated by special interest groups [7]: corporate interests which result in self-selected academic oligarchies (special interest groups) that influence clinical and scientific information. Members of special interest

\section{KARGER}

(C) 2018 S. Karger AG, Basel

E-Mail karger@karger.com

www.karger.com/pps groups, by virtue of their financial power and close ties with other members of the group, have the task of systematically preventing dissemination of data which may be in conflict with their interests [8]. Corporate powers fused with academic medicine to create an unhealthy alliance that works against objective reporting of clinical research, sets up meetings and symposia with the specific purpose of selling the participants to the sponsors, and substantially controls journals, medical associations, and related foundations (through direct support and/or advertising). The growth of evidence-based medicine, with its emphasis on systematic reviews and guidelines, provided an ideal ground for multiplying the effects of financial conflicts of interest in medicine [2,9]. Physicians have been forced to prescription patterns that are financially biased, detrimental, and costly, and that clash with clinical reality [2]. Independent clinical research, such as that funded by nonprofit research organizations, may be a threat to corporate interest. This has been taken care of: the more distant research is from clinical challenges, the less likely it is to disturb the marketing strategies of the industries [8]. The antidote to such developments is essentially political and has to do with what each one of us may do within medical societies and academia [8] and, in a more general sense, with the use of taxpayer's money [10].

Giovanni A. Fava, MD

Department of Psychology, University of Bologna Viale Berti Pichat 5

IT-40127 Bologna (Italy)

E-Mail giovanniandrea.fava@unibo.it 
However, the current crisis in clinical research is also intellectual. Feinstein [11] attributed its main roots to the decline of clinical medicine as the source of fundamental scientific challenges, which took place after World War II. "The preclinical sciences became detached from their clinical origins and were converted into 'basic biomedical sciences' with goals that often no longer aimed at mechanisms of disease, with investigators who often had no clinical training or responsibilities, and with results that often had no overt relationship to clinical phenomena" $[11$, p. 216]. In psychiatry, the progress of neuroscience in the past decades has often led to a belief that clinical problems were likely to be ultimately solved by this approach. An increasing number of psychiatrists are wondering, however, why the cures and clinical insights that neuroscience has promised have not taken place. Biological reductionism has resulted in an idealistic approach and in scientific roads to nowhere, which are quite far from the explanatory pluralism required by clinical practice [12].

This journal has always supported papers that were characterized by the "clinical factor": the degree and extent to which a journal article provides information to the clinician that may improve his/her practice [13]. For the past several years Richard Balon, with increasing difficulties, has been selecting articles published in psychiatric journals that may entail the clinical factor [14].

Psychotherapy and Psychosomatics continues to be the home of innovative clinical thinking at the interface of behavioral and medical sciences and of contributions that censorship would not permit to appear. It is also the home of critical thinking in the setting of systematic reviews characterized by artificial consensus of an endless list of authors, intellectual mediocrity, and ghost-writing [8]. Preserving intellectual freedom despite the proliferating connections between pharmaceutical and biotechnology industries and the physicians is a major ethical challenge of medicine today. The journal continues to seek medical papers characterized by the clinical factor and that develop clinical hypotheses. We deal with a broad range of clinical issues, particularly at an interdisciplinary level, related to assessment and treatment, with particular reference to psychotherapy and clinical pharmacopsychology [15]. Our limited space has forced us to develop a research letter section for contributions that we would not have the possibility of publishing as regular articles.

Is our emphasis on clinical papers and utility obsolete? It does not appear so. The journal has kept a top impact factor in 2016 (8.96), which places it as fourth in the Science Citation Index Psychology ranking and seventh in the Psychiatry ranking. These rankings, however, do not differentiate whether a journal is exclusively concerned with review articles (which are more likely to be cited) or publishes also original investigations. In the Science Citation Index Psychology ranking, the 3 journals preceding Psychotherapy and Psychosomatics are exclusively dedicated to review articles. This indicates that Psychotherapy and Psychosomatics is the top journal for original investigations in psychology.

Such an achievement is the result of several converging efforts. We should acknowledge here the perfect synchrony between Karger's editorial office and the associate editors, the work of the editorial board and statistical consultants, the help of many external reviewers (listed below) who dedicated their time and efforts to assess and improve the quality of submitted manuscripts, the skills of Emanuela Offidani and Andrea Sabbatini who prepared the press releases of the published articles, and the support of our authors and readers.

The following experts have supplemented the editorial board by reviewing the manuscripts submitted to Psychotherapy and Psychosomatics during 2017 and are gratefully acknowledged. Both external referees and editorial board members have disclosed potential conflicts of interests. The Editor-in-Chief and the Associate Editors have no conflict of interests to declare for 2017.

A. Abbass (Halifax, NS, Canada)

U. Albert (Turin, Italy)

P. Andrews (Hamilton, ON, Canada)

V. Balanza-Martines (Valencia, Spain)

R. Baldessarini (Belmont, CA, USA)

E. Baron Short (Charleston, SC, USA)

J. Bassoneault (Gainesville, FL, USA)

G. Benasi (Bologna, Italy)

T. Berger (Bern, Switzerland)

J.C. Beucke (Berlin, Germany)

C. Bockting (Utrecht, The Netherlands)

M. Bonomo (Bologna, Italy)

D. Borsboom (Amsterdam, The Netherlands)

L. Boschloo (Groningen, The Netherlands)

J. Boswell (Albany, NY, USA)

T. Brockmeyer (Düsseldorf, Germany)

P. Buckley (Richmond, VI, USA)

C. Buntrock (Erlangen, Germany)

M. Burg (New Haven, CT, USA)

R. Caceda (Little Rock, AR, USA)

F. Canneva (Erlangen, Germany)

V. Cardi (London, UK)

R. Carney (St. Louis, MO, USA)

D. Carrozzino (Chieti, Italy)

M. Casement (Eugene, OR, USA)

E. Chin-Bin (Prilly, Switzerland)

D. Clark (Oxford, UK)

J. Cohen (Pittsburgh, PA, USA)

L. Colloca (Baltimore, MD, USA)

L. Cosgrove (Boston, MA, USA)
2

Psychother Psychosom 2018;87:1-4 DOI: 10.1159/000485001
Fava/Cosci/Tomba 
P. Cromarty (Adelaide, SA, Australia)

C. Cusin (Boston, MA, USA)

R. Delle Chiaie (Rome, Italy)

P. de Jonge (Groningen, The Netherlands)

J. Denollet (Tilburg, The Netherlands)

D. Di Giacomo (L'Aquila, Italy)

A. Dingemans (Leiden, The Netherlands)

S. Dubovsky (Buffalo, NY, USA)

S. Erlandsson (Trollhättan, Sweden)

C. Fang (Taipei, Taiwan)

E. Fertuck (New York, NY, USA)

F. Galli (Milan, Italy)

H. Gerger (Basel, Switzerland)

J. Gervasi (Bologna, Italy)

S. Gostoli (Bologna, Italy)

L. Grassi (Ferrara, Italy)

H. Guendel (Ulm, Germany)

D. Hallford (Melbourne, VIC, Australia)

J. Hartmann (Melbourne, VIC, Australia)

M. Hautzinger (Tübingen, Germany)

U. Hegerl (Leipzig, Germany)

E. Hertenstein (Freiburg, Germany)

H. Hesser (Linköping, Sweden)

L. Hide (Brisbane, QLD, Australia)

W. Hiller (Mainz, Germany)

T. Hirvikoski (Stockholm, Sweden)

K. Honkalampi (Joensuu, Finland)

K. Huijbregts (Warnsveld, The Netherlands)

K. Humphreys (Stanford, CA, USA)

T. Hyphantis (Ioannina, Greece)

M. Irby (Winston-Salem, NC, USA)

R. Jarrett (Dallas, TX, USA)

L. Jelinek (Hamburg, Germany)

A. Jobst (Munich, Germany)

S. Johnson (Oslo, Norway)

R. Kathol (Minneapolis, MN, USA)

A. Khan (Bellevue, WA, USA)

Y. Khazaal (Geneva, Switzerland)

J.M. Kim (Gwangju, Republic of Korea)

J. Klein (Lübeck, Germany)

H. Kordy (Heidelberg, Germany)

P. Koval (Melbourne, VIC, Australia)

B. Krakow (Albuquerque, NM, USA)

I. Kronish (New York, NY, USA)

M. Lambert (Provo, UT, USA)

J. Lancee (Amsterdam, The Netherlands)

P. Leombruni (Turin, Italy)

J. Levenson (Pittsburgh, PA, USA)

M. Linden (Teltow/Berlin, Germany)

O. Luminet (Louvain, Belgium)

M. Lumley (Detroit, MI, USA)

P. Luyten (Louvain, Belgium)

A. Luszczynska (Warsaw, Poland)

A. Mannarino (Pittsburgh, PA, USA)

D. Mataix-Cols (Stockholm, Sweden)

A. Mattila (Tampere, Finland)

K. McHugh (Belmont, CA, USA)

K. Meissner (Munich, Germany)

S. Merry (Auckland, New Zealand)

M. Mikolajczak (Louvain, Belgium)
B. Milrod (New York, NY, USA)

R. Mojtabai (Baltimore, MD, USA)

J. Moncrieff (London, UK)

J. Murrough (New York, NY, USA)

R. Musil (Munich, Germany)

T. Nicholson (London, UK)

A. Nickerson (Sydney, NSW, Australia)

I. Niedtfeld (Mannheim, Germany)

A. Nierenberg (Boston, MA, USA)

V. Oertel-Knöchel (Frankfurt, Germany)

J. Ogrodniczuk (Vancouver, BC, Canada)

E. Offidani (New York, NY, USA)

V. Oliveira (Diamantina, Brazil)

S.D. Ostergaard (Risskov, Denmark)

P. Pacher (Bethesda, MD, USA)

A. Page (Perth, WA, Australia)

G. Paolisso (Naples, Italy)

L. Parkitny (Birmingham, AL, USA)

G. Patrinos (Patras, Greece)

D. Penzien (Winston-Salem, NC, USA)

C. Peretti (Paris, France)

A. Picardi (Rome, Italy)

A. Pinto (Bologna, Italy)

E. Premi (Brescia, Italy)

S. Priebe (London, UK)

T. Probst (Krems, Austria)

S. Radke (Aachen, Germany)

S. Rauch (Atlanta, GA, USA)

C. Reisz (Overland Parks, MO, USA)

V. Ricca (Florence, Italy)

S. Romans (Wellington, New Zealand)

A. Rush (Santa Fe, NM, USA)

M. Sack (Munich, Germany)

P. Salmon (Liverpool, UK)

V. Savarino (Genoa, Italy)

I. Schäfer (Hamburg, Germany)

B. Schrank (Tulln, Austria)

L. Sobrinho (Lisbon, Portugal)

N. Sonino (Padua, Italy)

F. Spengler (Bonn, Germany)

V. Starcevic (Sydney, NSW, Australia)

C. Steinert (Giessen, Germany)

B. Strauss (Jena, Germany)

L. Tecuta (Bologna, Italy)

M. Trivedi (Dallas, TX, USA)

C. Trudel-Fitzgerald (Boston, MA, USA)

A. van Balkom (Amsterdam, The Netherlands)

A. van Elburg (Zeist, The Netherlands)

C. Vazquez (Madrid, Spain)

D. Veale (London, UK)

M. Verrocchio (Chieti, Italy)

J. Vittengl (Kirksville, MO, USA)

A. Wagner (Toronto, ON, Canada)

M. Wolf (Zurich, Switzerland)

T. Wüstenberg (Berlin, Germany)

N. Yoshinaga (Miyazaki, Japan)

S. Zerwas (Chapel Hill, NC, USA)

T. Zheng (Guilin, China)

M. Zimmerman (Providence, RI, USA)

J. Zito (Baltimore, MD, USA) 


\section{References}

1 Engel GL: Physician scientists and scientific physicians. Am J Med 1987;82:107-111.

2 Fava GA: Evidence-based medicine was bound to fail: a report to Alvan Feinstein. J Clin Epidemiol 2017;84:3-7.

3 Ioannidis JPA: Evidence-based medicine has been hijacked: a report to David Sackett. J Clin Epidemiol 2016;73:82-86.

4 Engel GL: The need for a new medical model: a challenge for biomedicine. Science 1977; 196:129-136.

5 Fava GA, Sonino N: From the lesson of George Engel to current knowledge: the biopsychosocial model forty years later. Psychother Psychosom 2017;86:257-259.
6 Bobbio M, Bonaldi A, Lusiani L, Kidd E: The unbearable heaviness of reductionism: the paradigm of the antiatherogenic diet. Ital J Med 2017;11:322-324.

7 Fava GA: All our dreams are sold. Psychother Psychosom 1998;67:191-193.

8 Fava GA: The hidden costs of financial conflicts of interest in medicine. Psychother Psychosom 2016;85:65-70.

9 Melander H, Ahlqvist Rastad J, Meijer G, Beermann B: Evidence-biased medicine - selective reporting from studies sponsored by pharmaceutical industry. BMJ 2003;326: 1171-1173.
10 Sanders B: Our Revolution. New York, St. Martin's Press, 2016.

11 Feinstein AR: The intellectual crisis in clinical science. Perspect Biol Med 1987;30:215-230.

12 Fava GA: The intellectual crisis of psychiatric research. Psychother Psychosom 2006;75: 202-208.

13 Fava GA: The clinical factor. Psychother Psychosom 2011;80:1-3.

14 Balon R: The clinical factor 2016. Psychother Psychosom 2017;86:323-331.

15 Fava GA, Tomba E, Bech P: Clinical pharmacopsychology: conceptual foundations and emerging tasks. Psychother Psychosom 2017; 86:134-140. 